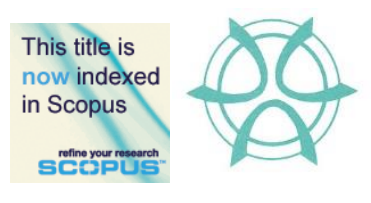

PLANNING MALAYSIA:

Journal of the Malaysian Institute of Planners

VOLUME 17 ISSUE 2 (2019), Page 259 - 266

\title{
CONCEPT OF PRIVACY FROM ISLAMIC PERSPECTIVE IN FLOOD EVACUATION CENTRE
}

\author{
Asiah Abdul Rahim ${ }^{1}$ \& Wan Mohamad Amin W Seman ${ }^{2}$ \\ ${ }^{1,2}$ Kulliyyah of Architecture and Environmental Design \\ INTERNATIONAL ISLAMIC UNIVERSITY OF MALAYSIA
}

\begin{abstract}
The flood events in Kelantan during December 2014 were examples of disasters in recent years that garnered national attention. Emergencies can occur with little or no warning. Floods deprive families of basic food and shelter, and lead to significant social and emotional impacts that linger long after the event. Every year, schools and community areas have been used as evacuation centres. A number of problems faced by the evacuees have been identified, especially in terms of physical facilities such as the lack of privacy for women and families, especially during night time. The objectives of this paper are as follows: (1) to study on the concept of privacy from an Islamic Perspective; and (2) to assess privacy in the context of a flood evacuation centre. The data gathered were tabulated. The research also utilised secondary data from literature. Data were analysed using content analysis and case studies. The data were analysed based on issues raised. Recommendations and suggestion are posed on overcoming the identified issues and problems. This research contributes a review of examples of evacuation facilities that follow Islamic teaching in the context of privacy in evacuation centres.
\end{abstract}

Keywords: privacy, islamic perspective, flood evacuation centre 
Asiah Abdul Rahim \& Wan Mohamad Amin W Seman

Concept of Privacy from Islamic Perspective in Flood Evacuation Centre

\section{INTRODUCTION}

\section{Definition of Privacy from Islamic Perspective}

In Islam, Qur'an and Sunnah (Hadith) are the primary sources of law and references. Qur'an and Sunnah provide important Islamic teachings and references on human privacy. As recorded in Hadith Arbain Nawawi, no. 12 by Tirmidhi, Prophet (peace be upon him) said "From the perfection of a person's good faith in Islam is leaving alone what does not concern him". The hadith shows the importance of being determined and concentrated to issues relevant and related to us to improve our capacity and capability.

Surah An-Nur, verses 27-28, mention that a person is not allowed to enter another's property if he or she does not have the permission from the property owners. The verses emphasise that it is solely and completely in the hand of the owner whether or not to allow someone to enter the area inside his/her house. Here, the area is obstructed with blocking elements such as protected walls or doors. Authorisation to deliver access limitation is explained in Surah An- Nur, verse 58. Tafsir Tabari mentioned the general rule from this verse, which indicated 'the slave' (whom your right hands possess) which can be either male or female, as well as those who have not yet reached puberty, need to ask permission if he or she wishes to access the area of 'their master', especially when the master is taking a rest during three types of privacy. The three types of privacy are (i) property, (ii) meeting, or (iii) conversation and evidence.

According to Marcus and Carter (2007), privacy is a clear specification of what is at stake (what is being kept private) and the parties against which privacy is being invoked (who should not be privy to the information being kept private). Islam protects the privacy of people tremendously. Human beings should be concerned only for their own responsibilities and their own businesses.

\section{Flood Evacuation Centre}

Floods cause the destruction of public facilities and properties. Based on the National Security Council (NSC), the massive flood that happened in Kelantan in 2014 was the worst in the history of Kelantan (Azlee, 2015). The water levels at most flood hit area superseded the last biggest flood of 1967, and evacuation and emergency sheltering were extremely challenging.

According to Bologna (2010), the safe evacuation of flood victims in Malaysia is one of the most important emergency response activities after the occurrence of floods or other disasters and hazards. Planning is a crucial component in any safety and health program including emergency action (Nik Nor Ronaidi, 2012).

The December 2014 Kelantan Flood was example of the natural disasters in recent years that have garnered national attention. Emergencies can occur suddenly with little or no warning. Such disasters deprive families of even the 
most basic needs such as food and shelter, and pose significant social and emotional impacts that linger long after the event. Schools and community areas have been used as evacuation centres. However a number of problems faced by the evacuees have been identified, especially in terms of physical facilities, such as lack of privacy for women and safety during night time. Privacy and safety are the main factors indicating unsuitable evacuation area especially for families and single women.

\section{The Function of Flood Evacuation Centres}

According to Somasundaram and Davies (2014), an evacuation centre is a place where the communities of disaster affected areas assemble. McInerny (2012) also added that evacuation centre is also equipped with technical, financial, social assistance and emotional support. Davis (1978) said that evacuation centre also is "a place used solely for receipt of service, or a staging point for future action". The identified services of evacuation centres include (Siti Falindah \& Nik Nadrul Hisham, 2015):
a. Food catering;
b. Health and safety;
c. Transportation, volunteers;
d. Site services;
e. Telecommunication; and
f. Special facilities for special needs.

\section{RESEARCH BACKGROUND}

Unsuitable evacuation centres are those which (The Malaysian Insider, 2014; Said, Gapor, Samian, \& Abd Aziz, 2013):

a. Use a school or multipurpose hall as evacuation centre;

b. Lack facilities and are not suitable for people to stay;

c. Have a shortage of essential necessity such as food;

d. Lack understanding between victims; and

e. Have overcrowded environment and insufficient and unsuitable infrastructures and equipment.

The lack of consideration for the disabled community in evacuation centre was described by a study by Asiah, Ismawi, Mohd Ramzi, Izawati and Che Zulkhairi (2015) as follows:

a. Evacuation centres are completely non-universal and completely inaccessible;

b. A lack of recognition and safety procedures in handling and locating frail senior citizens, people with disabilities and patients with physical conditions; and 
Asiah Abdul Rahim \& Wan Mohamad Amin W Seman

Concept of Privacy from Islamic Perspective in Flood Evacuation Centre

c. Lacking in privacy, safety and security, as well as a convenient privacy design that ensure the well-being of relocated disaster victims.

The objectives of this research are (i) to study on the concept of privacy and safety from Islamic Perspective in flood evacuation centres; and (ii) to assess the implementation of the concept of privacy in flood evacuation centres. The gathered data was tabulated. Secondary data was collected from literature review. The data was analysed using content analysis and case studies.

\section{IMPORTANCE OF PRIVACY IN FLOOD EVACUATION CENTRE}

Among important elements in building emergency relief centre are personal support and privacy area (Victoria Department of Human Services, 2013). The flood evacuation centre must be designed to protect and maintain the privacy of the affected people. The layout of the flood evacuation centre should have separated space and boundary for both males and females. The concept of boundary is important in planning and designing the architectural space (AbuGazzeh, 1993). Flood evacuation centres serve as a temporary home for the evacuees. Hence the centre must be designed with partitions that are convenient and can be promptly put up during flood. The partition could be a wall or a curtain depending on the size and structure of the flood evacuation centre.

Abu Gazzeh (1993) added that there are culture-specific, cognitivelyimportant practices that differ depending on the society in determining whether to put partition or segregation in the space. The facilities must offer the flood victims with individual living space to increase the level of privacy in the evacuation centre. By having a separated area, the evacuees, especially women, have the freedom to change clothes and sleep without fearing for their safety against the opposite gender.

\section{CURRENT PRACTICE OF FLOOD EVACUATION CENTRE IN MALAYSIA}

\section{Mercy Malaysia - Evacuation Centre in Perkampungan MERCY Tualang,} Kuala Krai, Kelantan, Malaysia

Perkampungan MERCY Tualang has 32 houses with variety of sizes based on evacuees' family size. During early construction, each house was built to a standard size, but as the household size of evacuees was different, MERCY provided a renovation programme that expanded the spaces for more comfort to accommodate larger family size.

Most of the family that stayed in Perkampungan MERCY Tualang were the flood victims from Kampung Bekok and Tualang, Kuala Krai. Flood victims tend to stay in Perkampungan MERCY Tualang around two years before they move to their permanent houses. Perkampungan MERCY Tualang has been 
PLANNING MALAYSIA

Journal of the Malaysia Institute of Planners (2019)

proposed to be turned into a Tahfiz School after all flood victims moved to their permanent houses. Perkampungan MERCY Tualang provided public toilets separated for both females and males. A pondok was provided as a space for social activities. The musolla is located at centre of the area for easy access. Each house was designed with one living room, one bedroom and a veranda. Based on observation, the houses lacked privacy as they are located too close to each other.

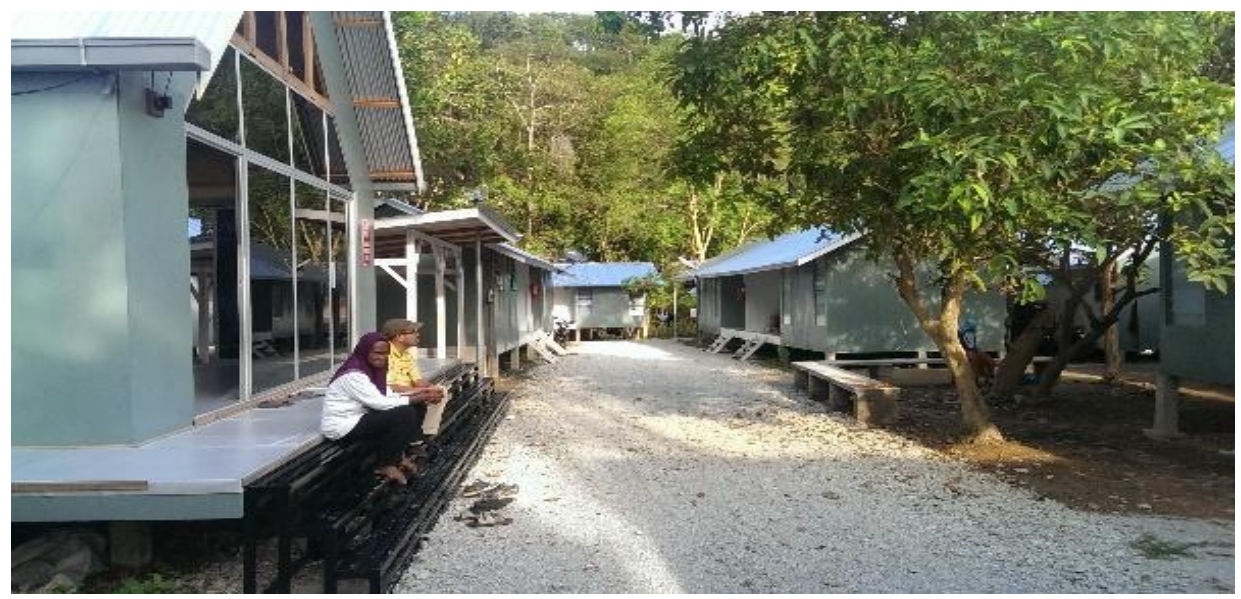

Figure 1 Facilities provided in Perkampungan MERCY Tualang, Kuala Krai, Kelantan. Source: Asiah et al.,2015

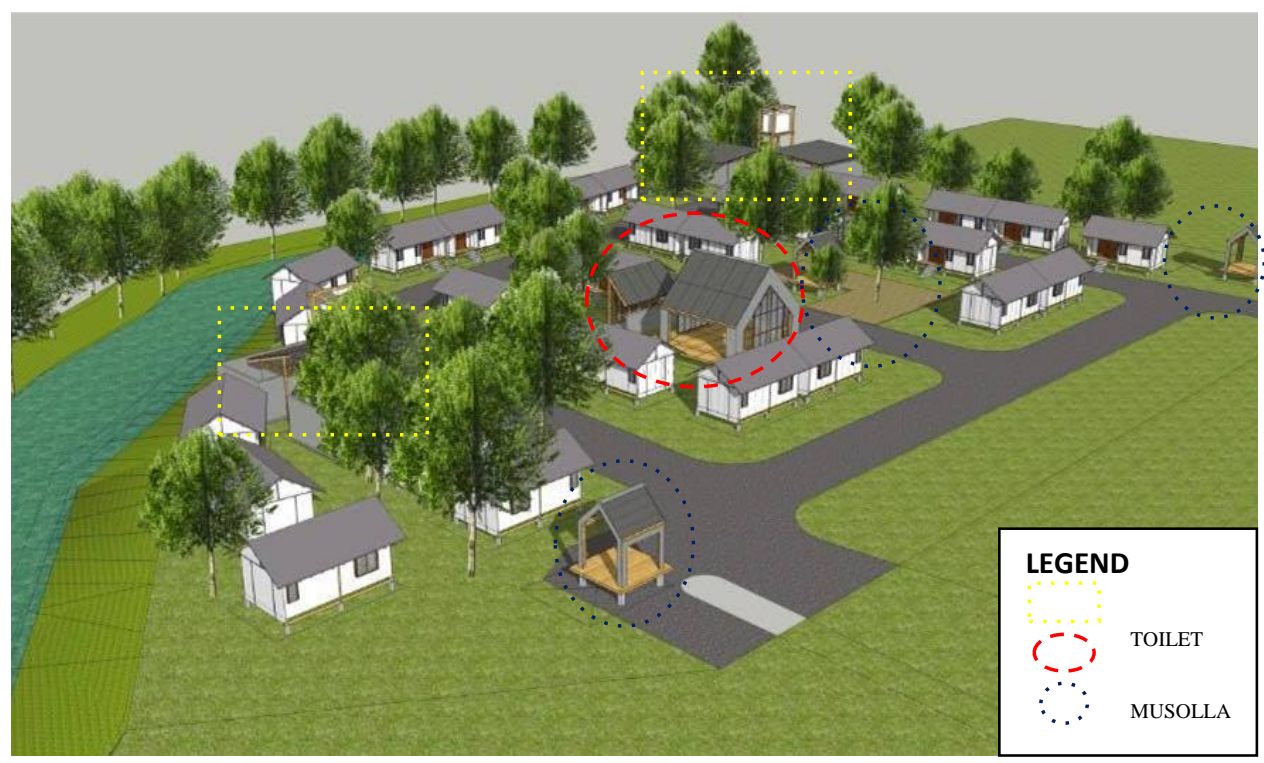

Figure 2: Diagram showing the facilities provided in Perkampungan MERCY Tualang, Kuala Krai, Kelantan.

Source: Asiah et al., 2015 
Asiah Abdul Rahim \& Wan Mohamad Amin W Seman

Concept of Privacy from Islamic Perspective in Flood Evacuation Centre

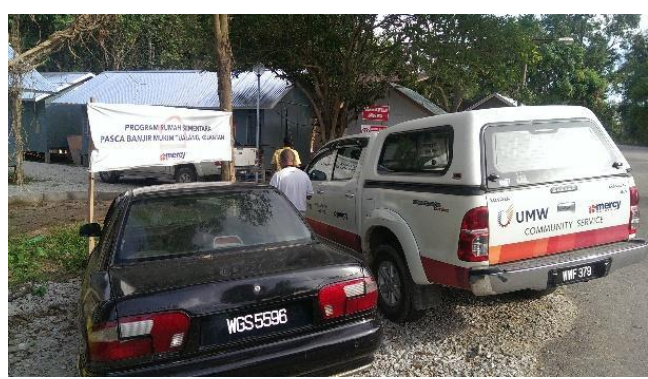

Figure 3: Front area of Perkampungan MERCY Tualang, Kuala Krai, Kelantan. Source: Asiah et al. (2015)

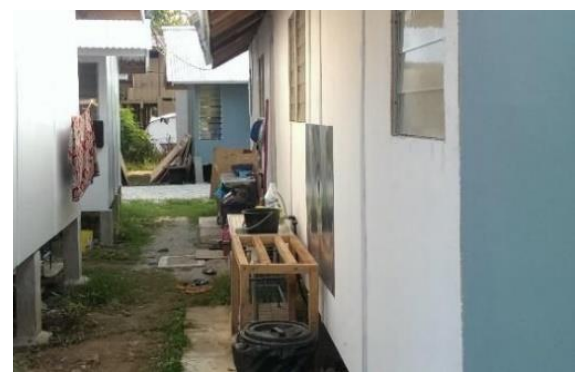

Figure4: House area of Perkampungan MERCY Tualang, Kuala Krai,

Kelantan.

Source: Asiah et al. (2015)

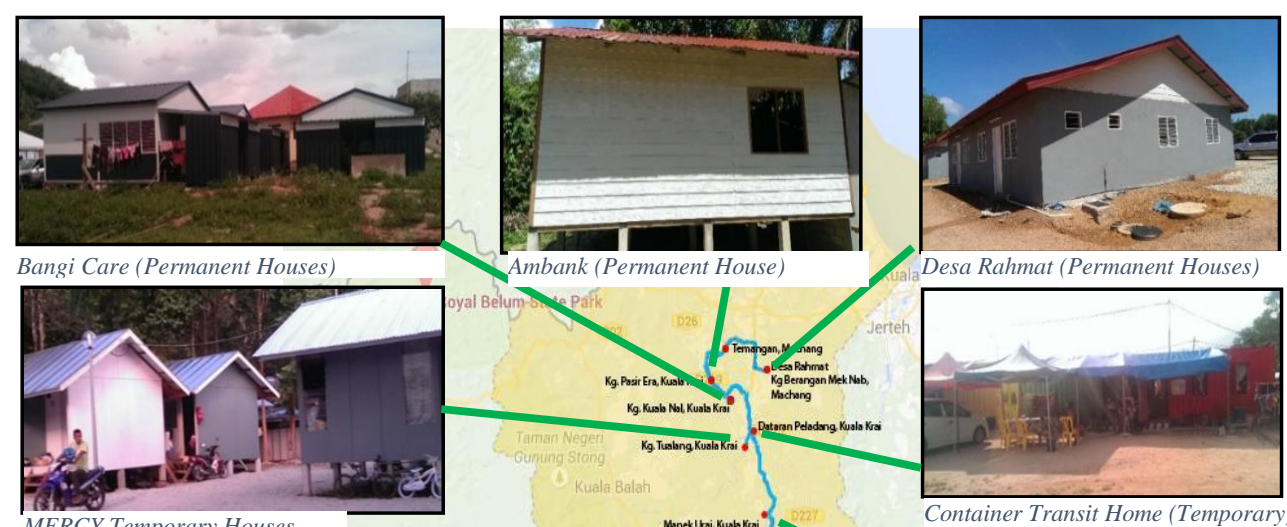

MERCY Temporary Houses

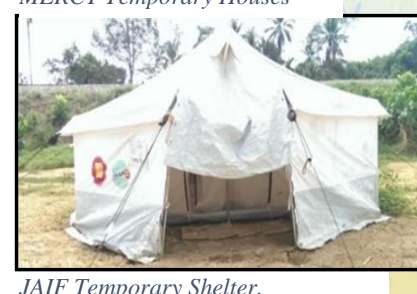

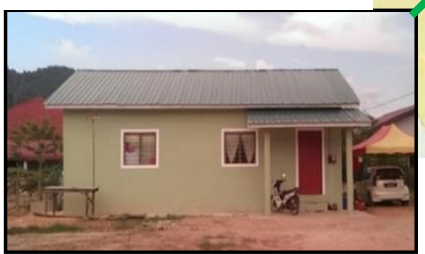

Rumah Budiman Permanent Houses.

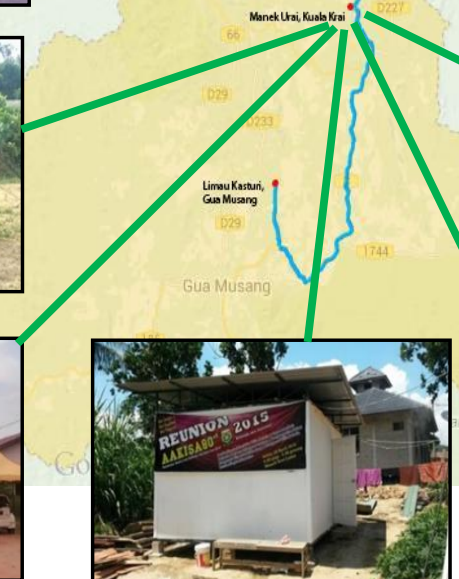

AAKISA Temporary Houses

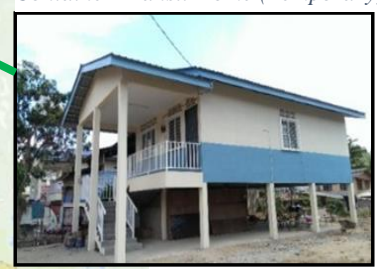

JKR Permanent Housermanent

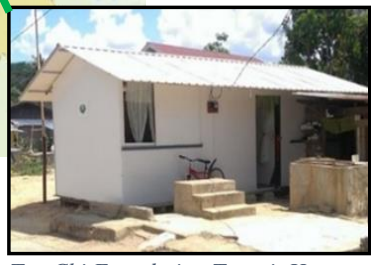

Tzu Chi Foundation Transit Home

Figure 5: Example of other flood evacuation centres in Kelantan, Malaysia. Source: Asiah et al. (2015) 
PLANNING MALAYSIA

Journal of the Malaysia Institute of Planners (2019)

According to Asiah et al. (2015), the shelters are divided into two categories, which are permanent structure shelters and temporary structure shelters. The weight of the building materials is an important factor. There is a significant difference between heavy structures and lightweight structures. The permanent structures are more comfortable compared to the temporary structures. The temporary structures lacked privacy features. Temporary houses are not comfortable to stay in as the building materials are not suitable for long stays. Segregation between males and females is also an issue. The distance between houses and the building material is not responsive to the lack of privacy issues.

\section{CONCLUSION AND RECOMMENDATION}

Based on the findings, it can be concluded that current evacuation centre is not properly designed to meet the need of people especially in terms of privacy. In Islamic teaching, privacy is an important architectural factor as it relates to covering the aurah. It is an obligation for Muslims to cover their aurah. Since a majority of Malaysians are Muslims, privacy features in evacuation centres should be taken seriously. This paper contributes a review of the existing evacuation facilities that need to be improved in terms of privacy based on Islamic teachings.

It is time for flood evacuation centres to be properly designed with careful consideration of the needs of the flood evacuees. The evacuation centre should be equipped with convenient facilities and accommodation that prevent chances of privacy intrusion. The right to privacy should be taken seriously when creating temporary living areas in evacuation centres. The study recommends improvement in the following areas: accessible toilets in mosques, community halls and schools; better connectivity between buildings and facilities; and privacy-sensitive design of temporary accommodation.

\section{REFERENCES}

Abu-Gazzeh, T. (1993). Privacy as the basis of architectural planning in the Islamic culture of Saudi Arabia. Architectural \& Behavioural Journal, 11(30), 269-288.

Asiah, A. R., Ismawi, Z., Mohd Ramzi, M. H., Izawati, T., \& Che Zulkhairi, A. (2015). User perception of mobile homes for shelter relief centre as a respond for flood disaster preparedness. (n.d.): Kementerian Pengajian Tinggi.

Azlee, A. (2015). Worst flood in Kelantan, confirms National Security Council (NSC). Retrieved from Malaymail at https://www.malaymail.com/s/813959/worstfloods-in-kelantan-confirms-nsc

Bologna, R. (2010). Planning and designing post disaster transitional housing: The case of the Abruzzo (Italy) earthquake. Proceedings TG63 - Special Track 18th CIB World Building Congress, Balford, UK.

Davis, I. R. (1978). Part one: Emergency shelter. The Role of Technology in International Disaster Assistance: Proceedings of the Committee on International Disaster Assistance Workshop. March 1977, Washington, DC. 
Asiah Abdul Rahim \& Wan Mohamad Amin W Seman

Concept of Privacy from Islamic Perspective in Flood Evacuation Centre

Marcus, J. S., \& Carter, K. (2007). Comparison of privacy and trust policies in the area of electronic communications. (n.p.): (n.p.).

McInerny, T. (2012). Emergency sheltering in Australia: Considerations beyond the four walls and a roof. Retrieved from https://www.redcross.org.au/getmedia/23ed0b6d-af70-4abb-bdf8d1e32f84d451/Emergency-sheltering-poster.pdf.aspx.

Nik Nor Ronaidi, N. M. (2012). Emergency response planning and implementation (PowerPoint slides). Retrieved from https://www.slideshare.net/NikRonaidi/emergency-response-planning-andimplementation-15685052

Said, M. Z, Gapor, S. A., Samian, M. N, \& Aziz, A. M. A, (2013). Konflik di pusat pemindahan banjir: Kajian kes di Daerah Padang Terap, Kedah. Malaysia Journal of Society and Space, 9(1), 61-69.

Siti Falindah, P., \& Nik Nadrul Hisham, N. R. (2015). The perceived quality and satisfaction with services at evacuation centres: The case of Kemaman Evacuation Centre. South East Asia Journal of Contemporary Business, Economics and Law, 8(2), 21-29.

Somasundaram, T., \& Davies, J. B. (2014). Collaboration to improve evacuation centre operations in Queensland. International Journal of Disaster Resilience in the Built Environment, 5(3), 305-317.

The Malaysian Insider (2014) http://www.themalaysianinsider.com/malaysia/article/over-65000-evacuatedas-floods-worsenbernama

Victoria Department of Human Services (2013). Emergency relief handbook: A planning guide. Melbourne: Author

Received: $12^{\text {th }}$ January 2019. Accepted: $2^{\text {nd }}$ August 2019 